\title{
ANALISIS SIFAT FISIK DAN KIMIA PATI DARI TIGA VARIETAS SUKUN (Artocarpus sp.)
}

\author{
Physical and Chemical Analysis of Starch Contained in Three Varieties \\ of Breadfruit (Artocarpus sp.)
}

\author{
Syane Palijama*, Josephina Talahatu dan Izaac Joshua Huwae \\ Jurusan Teknologi Hasil Pertanian Fakultas Pertanian Universitas Pattimura \\ Jl. Ir. M. Putuhena Kampus Poka Ambon 97233. \\ *Penulis Korespondensi: annie_jeanne@yahoo.com
}

\begin{abstract}
Breadfruit as an agricultural commodity with high carbohydrate content, can be functioned whether as a food reserve or as an alternative food resource. It also can improve diversity among food products and add value to the product as well, when it is being processed into starch. More ever, the process of making breadfruit into starch can reduce number of unused fruits as a result of bad fruit quality and rotten fruit. The starch can be used as a basic ingredient of various processed agricultural products. This research was aimed to analyze physical and chemical of starch contained in three breadfruit varieties. A completely randomized design was applied in this research with three levels of treatments, i.e.: 'batu' breadfruit starch (A1), 'duri' breadfruit starch (A2), and 'kapas' breadfruid starch (A3). Analyzed variables were water content, ash, amylase content, swelling power and solubility. Result indicated that 'batu' breadfruit starch had the highest value on variables of ash content, amylase content and solubility which were 0,09 percent, 19,67 percent and 24,07 percent respectively, while its water content and swelling power which were 3,74 percent and $17^{\prime} 37 \mathrm{~g} / \mathrm{g}$ was the lowest value among other breadfruit starch. The highest water content and swelling power which were 6,64 percent and $20,01 \mathrm{~g} / \mathrm{g}$ were found in 'duri' breadfruit starch.
\end{abstract}

Keywords: breadfruit, starch, variety

\begin{abstract}
ABSTRAK
Sukun (Artocarpus sp.) sebagai salah satu komoditas pertanian penghasil karbohidrat yang cukup tinggi dan berperan penting sebagai cadangan pangan ataupun sebagai bahan pangan alternatif. Pengolahan sukun menjadi pati dapat meningkatkan diversifikasi produk pangan dan dapat memberi nilai tambah dan mengangkat sukun menjadi komoditas yang bernilai tinggi. Selain itu, pengolahan sukun menjadi pati diharapkan dapat mengurangi jumlah sukun yang terbuang percuma karena rusak ataupun busuk, karena dapat berguna sebagai bahan utama olahan produk pertanian. Penelitian ini bertujuan untuk mengetahui sifat fisik dan kimia dari tiga varietas sukun. Rancangan yang digunakan adalah rancangan acak lengkap yaitu varietas sukun yang terdiri dari tiga perlakuan yaitu: A1 (Pati Sukun Batu), A2 (Pati Sukun Duri), dan A3 (Pati Sukun Kapas). Peubah yang diamati berupa kadar air, kadar abu, kadar amilosa, swelling power dan daya larut. Hasil penelitian ini menunjukkan bahwa; pati sukun batu (A1) memiliki kadar abu, kadar amilosa dan daya larut tertinggi masing-masing sebesar 0,09\%, 19,67\% dan 24,07\% dan memiliki kadar air dan swelling power terendah masing-masing sebesar 3,74\% dan $17,37 \mathrm{~g} / \mathrm{g}$. Pati sukun duri (A2) memiliki nilai kadaar air dan swelling power tertinggi masing-masing sebesar 6,64\% dan 20,01 g/g.
\end{abstract}

Kata kunci: pati, sukun, varietas 


\section{PENDAHULUAN}

Sukun (Artocarpus sp.) sebagai salah satu komoditas pertanian penghasil karbohidrat yang tinggi dan berperan penting sebagai cadangan pangan ataupun sebagai bahan pangan alternatif (Supriati, 2010). Pemanfaatan sukun sebagai bahan pangan semakin penting, sejak pemerintah mulai melancarkan program diversifikasi pangan. Sukun mengandung karbohidrat dan gizi yang baik seperti halnya ubi, gembili, gadung dan lain-lain. Kandungan karbohidrat sukun sama dengan beras, yaitu 78,9\% (Angkasa, 1994).

Buah sukun menjadi komoditas yang cukup penting karena produktivitasnya yang tinggi. Meskipun demikian, pemanfaatan buah sukun masih terbatas karena masalah penyimpanan yang sulit dalam bentuk buah segar. Oleh karena itu, salah satu upaya yang dilakukan adalah mengolahnya menjadi bahan setengah jadi berupa pati yang dapat diaplikasikan pada pembuatan produk-produk lainnya (Pratiwi et al., 2012)

Di Maluku khususnya di Desa Tial, Kecamatan Salahutu, Kabupaten Maluku Tengah terdapat tiga varietas sukun yang dibedakan berdasarkan sifat morfologi yaitu ukuran buah, bentuk buah dan kedudukan daun. Berdasarkan peninjauan langsung di lapangan ketiga varietas sukun tersebut dikenal secara lokal dengan nama sukun batu, sukun duri dan sukun kapas.

Pati sukun lebih dikenal sebagai aci sukun, di peroleh dengan cara ekstraksi. Menurut Peleg (1983), hasil ekstraksi apabila diklasifikasikan berdasarkan kandungan kimia disebut pati. Pati dalam penggunaannya sangat ditentukan oleh sifat fisik dan kimianya. Sifat fisik yang sangat berpengaruh adalah swelling power, daya larut, proses gelatinisasi, kejernihan pasta, stabilitas beku cair, dan lain-lain.

Pengolahan sukun menjadi pati dapat meningkatkan diversifikasi produk pangan dan dapat memberi nilai tambah dan mengangkat sukun menjadi komoditas yang bernilai tinggi. Selain itu, pengolahan sukun menjadi pati diharapkan dapat mengurangi jumlah sukun yang terbuang percuma karena rusak ataupun busuk, karena dapat berguna sebagai bahan utama olahan produk pertanian.

Melihat nilai produksi dan potensi sukun di Maluku cukup tinggi, serta prospeknya ke depan cukup menjanjikan maka perlu dilakukan upayaupaya pengendalian pengolahan berupa pengendalian sifat-sifat fisik dan kimia bahan pangan tersebut. Aplikasi pengolahan dilakukan sebagai salah satu metode teknologi bahan pangan yang efektif dalam memperpanjang daya awet dan umur simpan.

\section{METODE PENELITIAN}

\section{Bahan}

Bahan utama yang digunakan adalah sukun dengan tiga varietas yaitu batu, duri dan kapas.

\section{Tahapan Penelitian}

Adapun tahapan dalam pembuatan pati sukun yaitu buah sukun yang telah matang, dipilih yang baik, selanjutnya dikupas sekaligus dilakukan pembersihan terhadap bagian-bagian yang tidak dapat diproses antara lain bagian memar, rusak, tangkai buah dan bonggol atau hati, serta serat disekelilingnya. Daging buah sukun dicuci bersih sehingga bebas dari kotoran dan getah. Daging buah kemudian diparut segera dan direndam dalam air. Kemudian dilakukan penyaringan, untuk memisahkan pati dengan ampas. Pati diendapkan kemudian diaduk dan dilakukan filtrasi sebanyak tiga kali hingga air bening. Pati diendapkan selama 12 jam menggunakan akuades. Pati basah dikeringkan pada dalam oven pada suhu $40^{\circ} \mathrm{C}$ selama 24 jam. Pati sukun kering harus segera digiling dan diayak hingga menjadi pati yang halus. Pati yang telah diayak dikemas dalam plastik kedap udara.

\section{Karakteristik Sifat Fisikokimia}

Pengamatan yang dilakukan meliputi kadar air (AOAC, 1984), kadar abu (AOAC, 1984), kadar amilosa (AOAC, 1984), daya larut dan swelling power (Adebowale et al., 2005).

\section{Analisis Data}

Data hasil penelitian diuji secara statistik dengan menggunakan analisis keragaman sesuai dengan rancangan yang digunakan. Beda antara rataan perlakuan di uji dengan uji beda nyata jujur (BNJ) pada taraf 5\% untuk tiap peubah dengan pengaruh perlakuan nyata atau sangat nyata.

\section{HASIL DAN PEMBAHASAN}

\section{Kadar Air}

Kadar air pati sukun duri menunjukkan nilai tertinggi yaitu sebesar $6,64 \%$ dan berbeda nyata 
dengan pati sukun kapas sebesar 4,52\% dan nilai terendah sebesar $3,74 \%$ ditunjukkan oleh pati sukun batu.

Berdasarkan hasil Uji BNJ, perlakuan pati sukun batu berbeda nyata dengan pati sukun duri dan pati sukun kapas sedangkan perlakuan pati sukun duri juga berbeda nyata dengan pati sukun batu dan pati sukun kapas, antara perlakuan pati sukun batu dan perlakuan pati sukun kapas terdapat perbedaan yang nyata. Hal ini juga ditunjukkan pada Gambar 1.

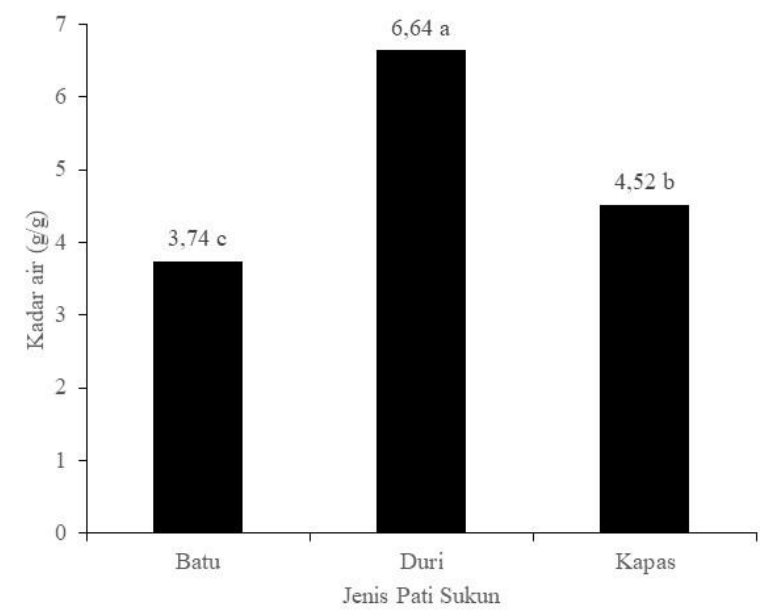

Gambar 1. Histogram pengaruh varietas terhadap kadar air pati sukun

Variasi nilai kadar air dari pati sukun, disebabkan oleh varietas buah sukun yang berbeda dan sifat morfologis tiap buah sukun. Menurut Hendalastuti dan Rojidin (2006), sukun duri memiliki nilai kadar air buah yang tinggi yaitu sebesar 80-90\%, dibandingkan dengan kedua varietas sukun yang lainnya yang nilai kadar air buah berkisar antara 40-50\%. Menurut Moorthy (2002), secara umum kadar air yang dimiliki pati kering bervariasi dari 6-16\%.

Hilangnya atau kurangnya kadar air pada pati sukun yang dihasilkan diduga karena pada proses pengolahan sukun menjadi pati telah mengalami proses pengolahan panas yaitu penjemuran atau pengeringan pati sehingga menyebabkan hilangnya air bebas dalam pati. Seperti yang dikatakan oleh Purnomo (1995), bahwa air bebas dapat dengan mudah hilang apabila terjadi penguapan atau pengeringan, sedangkan air terikat sulit dibebaskan. Menurut Widowati (2003), kadar air yang dimiliki pati sukun adalah sebesar $6-15 \%$ tergantung pada proses pengeringan pati.

\section{Kadar Abu}

Gambar 2 terlihat bahwa, kadar abu pati sukun menunjukkan nilai yang relatif sama. Kisaran kadar abu dari ketiga pati sukun (0,08-0,09\%) lebih rendah jika dibandingkan dengan penelitian Moorthy (2002) untuk beberapa jenis umbian seperti Dioscorea alata (0,22-0,26\%), Dioscorea esculenta (0,46\%), Dioscoro tundata $(0,19-0,46 \%)$, Dioscorea dumetorum (0,16-0,30\%) dan Coleus $(0,18-0,14 \%)$. Perbedaan ini disebabkan karena perbedaan kandungan mineral dalam jenis pati sukun. Perbedaan kandungan mineral dipengaruhi oleh kondisi tanah dan perbedaan penambahan pupuk (Wargiono, 1989).

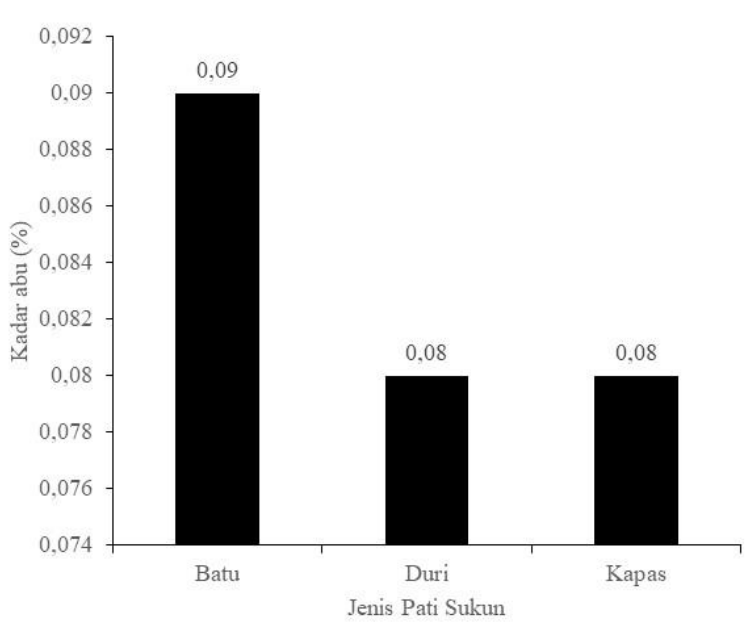

Gambar 2. Histogram pengaruh varietas terhadap kadar abu pati sukun

Kadar abu yang rendah juga berhubungan dengan proses pengolahan pati. Pati yang diperoleh dari hasil ekstraksi dan melalui tahapan pencucian berulang-ulang dengan air, pencucian tersebut dapat menyebabkan terlarutnya mineral dalam pati sukun oleh air sehingga kandungan mineral hilang bersama ampas.

Pengukuran kadar abu bertujuan untuk mengetahui besarnya kandungan mineral bahan pangan. Menurut Sudarmadji et al. (1996), salah satu tujuan penentuan kadar abu adalah sebagai parameter nilai gizi bahan makanan. Berdasarkan penelitian Moorthy (2002), kadar abu untuk pati berkisar antara 0,02-0,49\%.

\section{Kadar Amilosa}

Kadar amilosa pati Sukun batu mempunyai nilai tertinggi sebesar $19,67 \%$ jika dibandingkan 
dengan pati sukun duri sebesar $19,55 \%$ dan pati sukun kapas sebesar 19,36\% (Gambar 3). Berdasarkan hasil analisa, terlihat bahwa nilai kadar amilosa memiliki nilai yang relatif sama, berkkisar antara 19,36-19,67\%. Nilai ini lebih rendah jika dibandingkan dengan kadar amilosa pati ubi jalar hasil penelitian Tian et al. (1991) sebesar 17,5$38 \%$, pati ubi kayu sebesar 13,6-23,8\% (Moorthy, 2002) dan juga pati kayu sebesar $22,37-30,16 \%$ (Augustyn et al., 2007). Hal ini dapat saja terjadi karena adanya perbedaan tempat tumbuh, jenis varietas sukun sehingga faktor lingkungan mempengaruhi kadar amilosa yang dikandung.

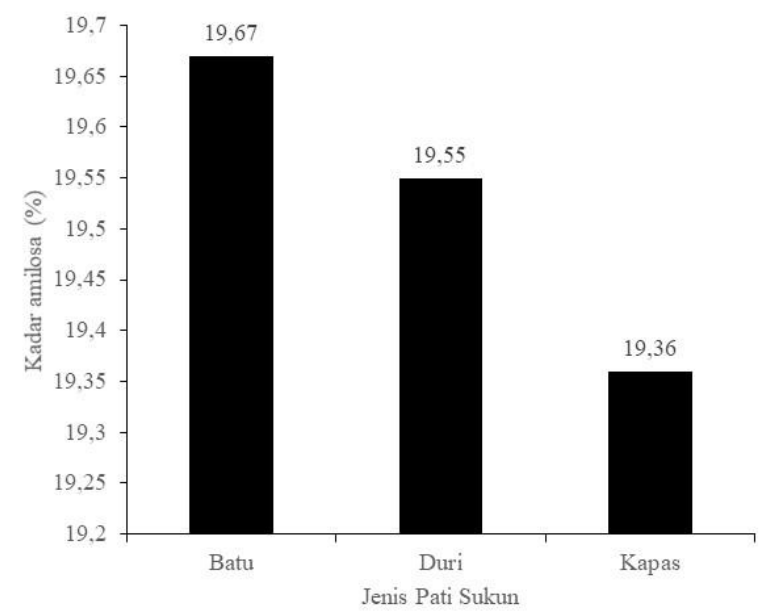

Gambar 3. Histogram pengaruh varietas terhadap kadar amilosa pati sukun

Pati terdiri atas dua kompoanen yang dapat dipisahkan, yaitu amilosa dan amilopektin. Perbandingan amilosa dan amilopektin secara umum adalah $20 \%$ dan $80 \%$ dari jumlah pati total. Adebowale dan Lawal (2003) mengemukakan bahwa sifat-sifat fungsional pati sangat dipengaruhi oleh konsentrasi amilosa yang tinggi.

\section{Daya Larut}

Berdasarkan hasil analisa keragaman terhadap daya larut pati sukun, diperoleh bahwa jenis pati sukun memberikan pengaruh tidak nyata. Daya larut pati sukun batu $(24,073 \%)$ memiliki nilai tertinggi jika dibandingkan pati sukun duri $(21,921 \%)$ dan pati sukun kapas $(21,674 \%)$. Daya larut diukur berdasakan berat kandungan kristal gula setelah dikeringkan supernatan.

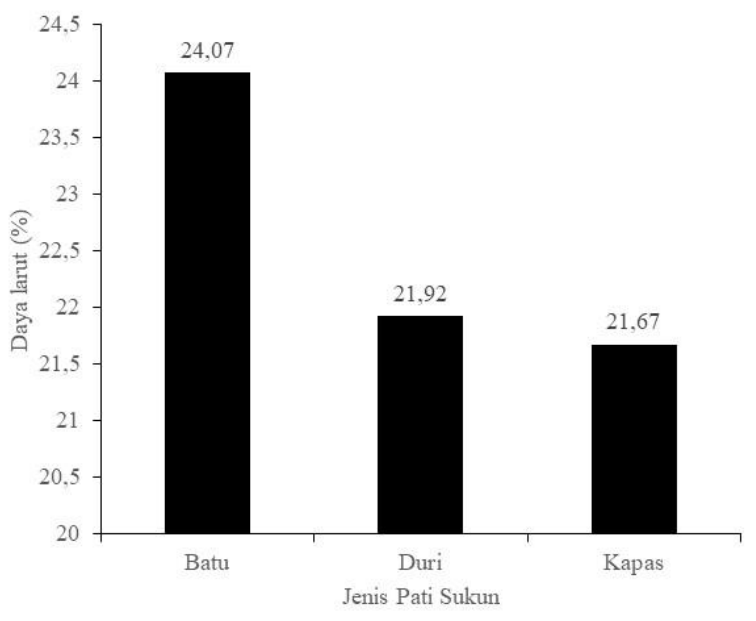

Gambar 4. Histogram pengaruh varietas terhadap daya larut pati sukun

\section{Swelling Power}

Swelling power pati sukun duri $(20,03 \mathrm{~g} / \mathrm{g})$ memiliki nilai tertinggi jika dibandingkan dengan swelling power pati sukun kapas $(19,99 \mathrm{~g} / \mathrm{g})$ dan pati sukun batu $(17,36 \mathrm{~g} / \mathrm{g})$ yang ditunjukkan pada. Berdasarkan hasil analisa dapat dilihat bahwa nilai tertinggi swelling power yaitu pati sukun duri sebesar 20,01 g/g dan terendah pada pati sukun batu sebesar 17,36 g/g swelling power menunjukkan bahwa seberapa besar pati dapat menggelembung yang ditunjukkan melalui perubahan berat karena penyerapan air oleh granula pati. Dapat dijelaskan pula bahwa penggelembungan pati dapat dihambat dengan amilosa yang tinggi (Wu dan Seib, 1990).

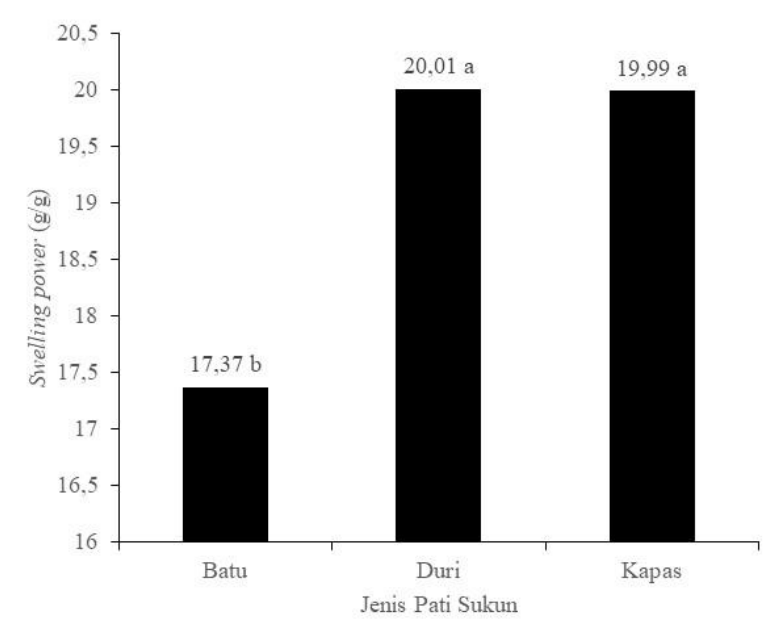

Gambar 5. Histogram pengaruh varietas terhadap kadar swelling power pati sukun 


\section{KESIMPULAN}

Perlakuan jenis pati sukun berpengaruh sangat nyata terhadap sifat-sifat yaitu kadar air dan swelling power, serta tidak berpengaruh nyata terhadap kadar abu, kadar amilosa dan daya larut.

Pati sukun batu memiliki kadar air sebesar 3,74\%, kadar abu 0,09\%, kadar amilosa 19,67\%, daya larut $24,07 \%$ dan swelling power sebesar 17,37 g/g. Pati sukun duri memiliki kadar air sebesar 6,64\%, kadar abu 0,08\%, kadar amilosa $19,55 \%$, daya larut $21,92 \%$ dan swelling power sebesar 20,01 g/g. Pati sukun kapas memiliki kadar air sebesar $4,52 \%$, kadar abu $0,08 \%$, kadar amilosa $19,36 \%$, daya larut $21,67 \%$ dan swelling power sebesar $19,99 \mathrm{~g} / \mathrm{g}$.

Pati sukun batu memiliki nilai kelarutan yang lebih baik bila dibandingkan dengan kedua pati sukun lainnya yaitu sebesar $24,07 \%$.

\section{DAFTAR PUSTAKA}

Adebowale, K.O., B.I. Olu-Owolabi, E.K. Olawumi, and O.S. Lawal. 2005. Functional properties of native, physically and chemically modified breadfruit (Artocarpus artilis) starch. Industrial Crops and Products 21: 343-351. https://doi.org/10.1016/j.indcrop.2004.05.00 2

Adebowale, K.O. and O.S. Lawal. 2003. Microstructure, physicochemical properties and retrogradation behaviour of mucuna bean (Mucuna pruriens) starch on heat moisture treatments. Food Hydrocolloids 17: 265-272. https://doi.org/10.1016/S0268005X(02)00076-0

Angkasa, S. 1994. Sukun dan Keluwih. Penerbit Penebar Swadaya. Jakarta.

[AOAC] Association of Official Analytical Chemist. 1984. Official Methods of Analysis of the Association of Official Analytical

Augustyn, G.H., F.J. Polnaya, dan A. Parinusa. 2007. Karakterisasi beberapa sifat pati ubi kayu (Manihot esculenta, Crantz). Buletin Penelitian BIAM 3: 35-39.

Chemist. $14^{\text {th }} e d$. AOAC Inc. Arlington. Virginia.
Hendalastuti, H. dan Rojidin. 2006. Karakteristik budidaya dan pengolahan buah sukun: Studi Kasus di Solok dan Kampar. Prosiding Seminar Litbang Hasil Hutan 220-230.

Moorthy, S.N. 2002. Physicochemical and functional properties of tropical tuber starches: A review. Starch/Stärke 54: 559592.

Peleg, M. 1983. Physical Characteristics of Food Powders. In: Peleg, M. and E.B. Bagley (eds). Physical Properties of Foods.AVI Publishing Company, Inc. Westport, Connecticut.

Pratiwi, D.P., A. Sulaeman, and L. Amalia. 2012. Pemanfaatan tepung sukun (Artocarpus altilis sp.) pada pembuatan aneka kudapan sebagai alternatif makanan bergizi untuk PMT-AS. Jurnal Gizi dan Pangan 7: 175180.

Purnomo, H. 1995. Aktivitas Air dan Peranannya dalam Pengawetan Pangan. Universitas Indonesia. Jakarta.

Sudarmadji, S., B. Haryono, and Suhardi. 1996. Analisa Bahan Makanan dan Pertanian. Penerbit Liberty. Yogyakarta.

Supriati, Y. 2010. Sukun sebagai sumber pangan alternatif substitusi beras. Iptek Tanaman Pangan 5: 219-231.

Tian, S.J., J.E. Rickard, and J.M.V. Blanshard. 1991. Physicochemical properties of sweet potato starch. Journal of the Science of Food and Agriculture 57:459-491. https://doi.org/10.1002/jsfa.2740570402

Wargiono, J. 1989. Budidaya Ubi Jalar. Bhratara. Jakarta.

Widowati, S. 2003. Prospek Tepung Sukun untuk Berbagai Produk Makanan Olahan dalam Upaya Diversifikasi Pangan. Makalah Falsafah Sains, Program Pasca Sarjana, Institut Pertanian Bogor.

Wu, Y. and P.A. Seib. 1990. Acetylated and hydroxypropylated distarch phospates from waxy barley: Paste properties and freezethaw stability. Cereal Chemistry 67: 202208. 